the cardiac catheterization laboratory allows monitoring of hemodynamics.

In the present study, the combined use of autologous blood donation at cardiac catheterization and treatment with recombinant human erythropoietin in acyanotic patients resulted in a high percentage of transfusion-free operations. Therefore this method may be useful in preventing transfusion-transmitted diseases. In contrast, in cyanotic patients, the transfusion-free surgery rate was low despite high blood erythropoietin concentrations and high recovery rate from anemia after autologous bloodcollection until the operation. On the basis of our findings, the strategy for transfusion-free cardiac operations for cyanotic patients should be examined further.

\section{REFERENCES}

1. Sandrelli L, Pardini A, Lorusso R, Sala ML, Licenziati M, Alfieri O. Impact of autologous blood predonation on a comprehensive blood conservation program. Ann Thorac Surg 1995;59:730-5.

2. Dodd RY. The risk of transfusion-mediated infection. N Engl J Med 1992;327:419-20.

3. Tasaki T, Ohto H, Hashimoto C, Abe R, Saitoh A, Kikuchi S. Recombinant human erythropoietin for autologous blood donation: effects on perioperative red-blood-cell and serum erythropoietin production. Lancet 1992;339:773-5.

4. Magilligan DJ. Indication for ultrafiltration in the cardiac surgical patient. J Thorac Cardiovasc Surg 1985;89:183-9.

\title{
SUCCESSFUL BRIDGING TO CARDIAC TRANSPLANTATION IN A DYSTROPHIC INFANT WITH THE USE OF A NEW PARACORPOREAL PNEUMATIC PUMP
}

\author{
Michael Weyand, MD, ${ }^{a}$ Deniz Kececioglu, MD, ${ }^{\mathrm{b}}$ Christof Schmid, MD, ${ }^{\mathrm{a}}$ Hans G. Kehl, MD, ${ }^{\mathrm{b}}$ Rene Tandler, MD, ${ }^{\mathrm{a}}$ \\ Heinz Michael Loick, MD, ${ }^{\mathrm{c}}$ and Hans H. Scheld, MD, ${ }^{a}$ Meunster, Germany
}

During the past decade, treatment of end-stage cardiac failure in adult patients with different forms of paracorporeal or implantable mechanical assist devices used as bridges to transplantation has become routine in many centers throughout the world. Survival after bridging and consecutive heart transplantation is comparable with that of nonbridged recipients if mechanical assistance lasts long enough to allow complete recovery of secondary organ dysfunction. However, no such mechanical assist device was available for neonates and smaller infants because of size incompatibility until recently. ${ }^{1-3}$ We report on our first experience with the MEDOS HIA system (MEDOS GmbH, Steinfurth, Germany) as a bridge to cardiac transplantation in a dystrophic infant, followed by successful cardiac transplantation.

A female child weighing $3490 \mathrm{gm}$ was born on June 6 , 1996. Delivery (Apgar scores at 1, 5, and 10 minutes were 10 ) and the early postpartum period was uneventful. At the age of 9 weeks, however, the child began having fever, shortness of breath, and sinus tachycardia. A chest $\mathrm{x}$-ray film demonstrated right lower lobe infiltration suggestive

From the Departments of Cardiothoracic Surgery, ${ }^{\text {a }}$ Pediatric Cardiology, ${ }^{\mathrm{b}}$ and Anesthesia and Operative Intensive Care, ${ }^{\mathrm{c}}$ Westfaelische Wilhelms Universitaet Muenster, Muenster, Germany.

Address for reprints: Michael Weyand, MD, Westfaelische Wilhelms Universitaet Muenster, Albert Schweitzer Straße 33, 48129 Muenster, Germany.

J Thorac Cardiovasc Surg 1997;114:505-7

Copyright (C) 1997 by Mosby-Year Book, Inc.

$0022-5223 / 97 \$ 5.00+0 \quad \mathbf{1 2 / 5 4 / 8 2 0 9 4}$ of pneumonia but, more important, a silhouette of a huge heart. After referral to our institution, echocardiography confirmed massive enlargement of both ventricles. Left ventricular fractional shortening was calculated as $8 \%$. Because she was in New York Heart Association class III-IV, the child was treated with digitalis, diuretics, and supportive oxygen at first. However, as the child's condition deteriorated further, with weight loss despite hypercaloric feeding and requirement of intravenous dopamine and dopexamine, she was listed for cardiac transplantation. The diagnosis was dilative cardiomyopathy, because no evidence of viral myocarditis was obtained. After 5 months on the waiting list, the child (3400 gm) had two episodes of cardiovascular collapse necessitating external heart massage and high-dose catecholamine support, as well as intubation and mechanical ventilation. Because no donor heart was available, the decision was made to use the paracorporeal MEDOS HIA system. Normothermic extracorporeal circulation was established with the use of a single atrial cannula. The arterial cannula was inserted into the proximal part of the aortic arch, leaving the ascending aorta untouched for the assist device. With the heart beating, a right-angled $18 \mathrm{~F}$ venous cannula was placed into the left atrium via the intraatrial groove, secured by two purse-string sutures of 5-0 monofilament polypropylene. ${ }^{4,5}$ The cannula was tunneled below the right costal margin to exit the skin in the right epigastrium. The arterial $18 \mathrm{~F}$ cannula was connected to the ascending aorta via a $4 \mathrm{~mm}$ polytetrafluorethylene graft, which exited the skin in the left epigastrium. After meticulous deairing, both tubes were connected to the $10 \mathrm{ml}$ paracorporeal ventricle placed onto the abdominal wall. The air driveline was connected to the console, left ventricular assist 


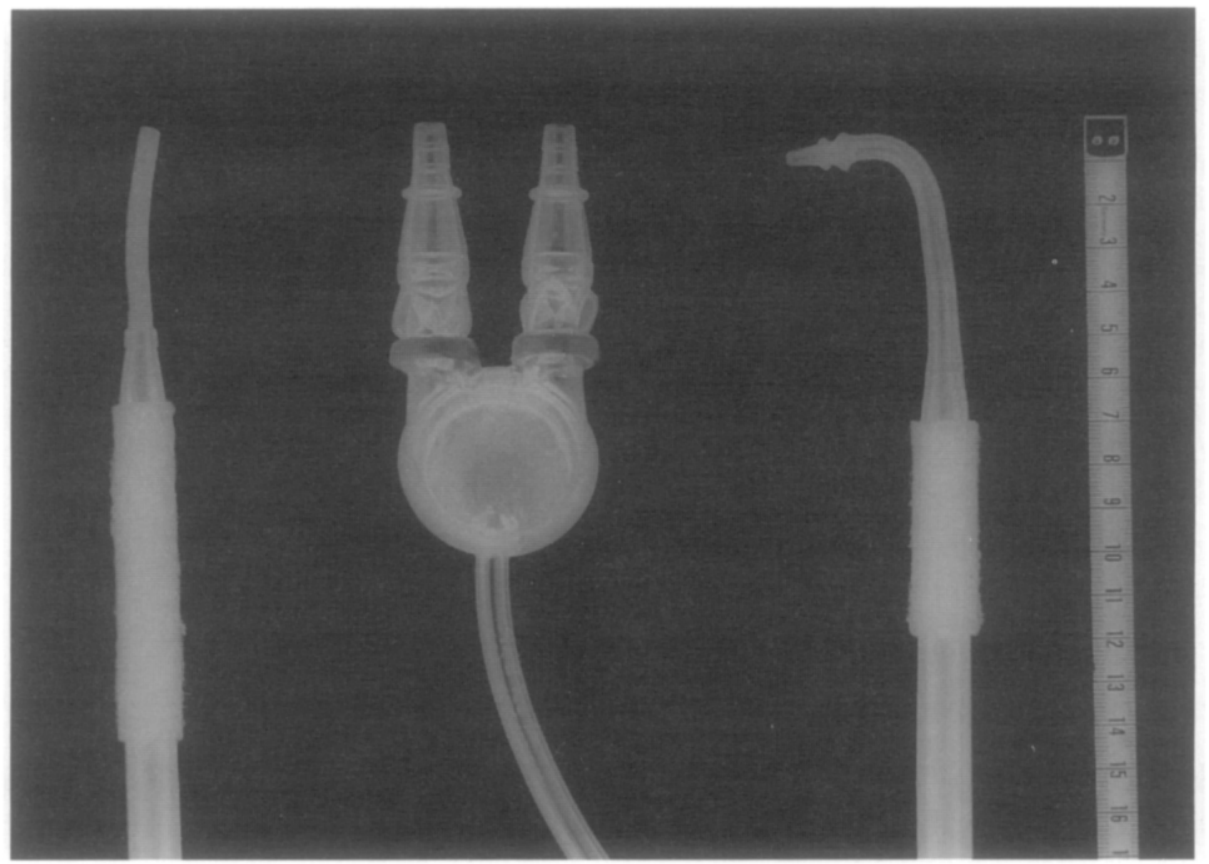

Fig. 1. Comparative depiction of the $18 \mathrm{~F}$ inflow cannula (left), the $10 \mathrm{ml}$ pump chamber (center), and the outflow cannula with its attached $4 \mathrm{~mm}$ polytetrafluoroethylene conduit (right) used in our case.

was started at a fixed rate of 70 beats/min, and extracorporeal circulation was stopped. The initial settings of the pump allowed for a pump output of $700 \mathrm{ml} / \mathrm{min}$, which corresponded to a cardiac index of $3 \mathrm{~L} / \mathrm{min}$ per square meter. Hemostasis was achieved and the chest closed by a polytetrafluoroethylene membrane sutured to the skin, because closure of the sternum was not possible (Fig. 1).

During the following 14 days of left ventricular support, the child continued to be supported by mechanical ventilation. Anticoagulation was achieved with intravenous heparin, aiming at an activated clotting time of 180 seconds. The child was closely monitored for signs of infection, and antibiotic prophylaxis was instituted with intravenous polyvalent immunoglobulins and a third-generation cephalosporin. Secondary organ function remained stable throughout the period of mechanical support. However, two episodes of bleeding resulting from erosion of small mediastinal vessels necessitated reexploration on postoperative days 3 and 5 . On day 7 , cerebral thromboembolism resulted in left-sided hemiplegia, presumably related to mobilization of a left ventricular (intracardiac) thrombus that had developed during a brief period of inadequate anticoagulation. Because minimal thrombus formation was also visible in the pump chamber, as well as in one of the inflow sinuses, the pump chamber was changed immediately.

After 14 days of mechanical support, a donor heart from a child with intracranial bleeding was procured. Total orthotopic transplantation with bicaval and pulmonary vein anastomoses was performed with moderate hypothermia with a graft ischemic time of 195 minutes. The postoperative clinical course was uneventful, based on standard triple-drug immunosuppression with cyclo- sporine, azathioprine, and steroids. Daily echocardiographic studies demonstrated sufficient and later continuously improving right ventricular function. Initial inotropic support could be reduced within 1 day and withdrawn within 1 week of support. Within a follow-up of 4 weeks, no episodes of rejection or infection were evident. On postoperative day 30 , hemiplegia had almost completely resolved and the infant was discharged to her home with weight gain and increasing physical activity.

The experience of mechanical support in infants is small and restricted to few centers in Europe. To our knowledge, this is the first report ever dealing with a successful bridging procedure in an infant with the weight and size of a neonate. The MEDOS HIA ventricular assist device is a pneumatic diaphragm pump completely made of polyurethane, including the inflow and outflow valves that house in a conduit simulating the aortic sinuses. Pump chambers are available at volumes of 9 and $10 \mathrm{ml}$, at 22.5 and $25 \mathrm{ml}$, and at 54 and $60 \mathrm{ml}$, respectively, for right and left or biventricular support for neonatal, infant, or adult patients. Both inflow and outflow conduits are simple to place into the left atrium and the ascending aorta. $\mathrm{Re}$ moval at the time of transplantation is similarly easy to achieve. In summary, the new MEDOS HIA system seems to offer a reliable instrument for mechanical support, even in neonates, when hemodynamic stability cannot be maintained by other means.

\section{REFERENCES}

1. Rakhorst G, Hensens AG, Verkerke GJ, Blanksma PK, Bom VJJ, Elstrodt J, et al. In-vivo evaluation of the HIA-VAD: a 
new German ventricular assist device. Thorac Cardiovasc Surg 1994;42:136-40.

2. Eilers R, Harbott P, Reul H, Rakhorst G, Rau G. Design improvements of the HIA-VAD based on animal experiments. Artif Organs 1994;18:438-73.

3. Tandler R, Deng MC, Schmid C, Scheld HH. Novacor LVAD bridge to transplantation in peripartum cardiomyopathy. Eur J Cardiothorac Surg. In press.
4. Scheld HH, Hammel D, Schmid C, Weyand M, Deng MC, Möllhoff $\mathrm{T}$, et al. Beating heart implantation of a wearable Novacor left-ventricular assist device. Thorac Cardiovasc Surg 1996;44:62-6.

5. Weyand M, Hammel D, Hoffmeier A, Loeher A, Frye K, Kerber $\mathrm{S}$, et al. Erfahrungen mit dem tragbaren Links-HerzUnterstützungssystem NOVACOR N 100. Transplantationsmedizin 1994;6:245-52.

\section{INTRAOPERATIVE PATENCY CONTROL OF ARTERIAL GRAFTS IN MINIMALLY INVASIVE CORONARY ARTERY BYPASS GRAFT OPERATIONS BY MEANS OF ENDOSCOPIC THERMAL CORONARY ANGIOGRAPHY}

Volkmar Falk, MD, Anno Diegeler, MD, Thomas Walther, MD, Hugo Kitzinger, Jacques A. M. van Son, MD, PhD, Rüdiger Autschbach, MD, PhD, and Friedrich W. Mohr, MD, PhD, Leipzig, Germany

Intraoperative patency control of internal thoracic artery (ITA) grafts in minimally invasive direct coronary artery bypass graft (MIDCAB) operations is hampered by a limited surgical access. A new method to intraoperatively assess graft patency was developed with the use of an endoscopic thermal scanner that can be operated through a port or inserted directly through a small thoracotomy incision.

Methods. MIDCAB operations with the ITA to graft the left anterior descending coronary artery (LAD) were performed in six male patients (aged 52 to 68 years) with isolated disease of the LAD. Four patients had a history of single or multiple percutaneous angioplasties. Left ventricular function was within normal limits in all patients (ejection fraction $>50 \%$ ). Patients were anesthetized and placed in a supine position. Through a small anterolateral thoracotomy $(6$ to $8 \mathrm{~cm})$ in the fourth intercostal space, the ITA was harvested. Two patients underwent cardiopulmonary bypass with endoaortic clamping and cardioplegic arrest by means of the Port-Access System (Heartport, Inc., Redwood City, Calif.). ${ }^{1}$ In the other four patients we operated on

From the Department of Cardiac Surgery, Heartcenter, University of Leipzig, Leipzig, Germany.

Received for publication March 11, 1997; accepted for publication March 17, 1997.

Address for reprints: Volkmar Falk, MD, Klinik für Herzchirurgie, Universität Leipzig, Herzzentrum, Russenstraße 19, 04289 Leipzig, Germany.

J Thorac Cardiovase Surg 1997;114:507-9

Copyright (C) 1997 by Mosby-Year Book, Inc.

0022-5223/97 $\$ 5.00+0 \quad \mathbf{1 2 / 5 4 / 8 2 0 9 5}$ the beating heart with temporary LAD occlusion and local ventricular wall immobilization using the CTS system (Cardio Thoracic Systems, Cupertino, Calif.). ${ }^{2}$ After completion of the distal anastomosis and before release of the vascular clamp, an endoscopic thermal scanner (Infracam, Inframetrics, North Billerica, Mass.) was introduced through the thoracotomy incision. The scanner based on a platinum silicon (PtSi) focal plane array detector $(256 \times 256$ elements $)$ operates at a wavelength of 3.4 to $5.0 \mu \mathrm{m}$ (mid-infrared spectrum) with a spatial resolution of $0.6 \mathrm{mrad}$. A $30 \mathrm{~cm}$ endoscope with an indium antimony ( $\mathrm{InSb}$ ) lens allows the scanner to operate through a $10 \mathrm{~mm}$ port. After placement of the endoscope above the surface of the heart and after local topical cooling, the vascular clamp on the ITA graft was released. The thermal gradient generated by the inflow of warm blood through the graft delineated the anastomosis and the distal vascular bed. The resulting heat picture was transformed online into an angiographic picture on a conventional video screen. In all patients graft flow was also confirmed by transittime Doppler-flow measurements (Transonic Systems Inc., Ithaca, N.Y.). All patients underwent a second angiogram before discharge (postoperative days 3 to 6).

Results. All operations were uneventful. Median ITA takedown was 33 minutes and median operation time was 117 minutes. Placement of the endoscope was performed through the thoracotomy incision in all cases. Fig. 1 shows a typical intraoperative thermal angiogram of an ITA graft to the LAD that was performed on the beating heart. Before release of the vascular clamp, the surface of the heart shows a homogeneous temperature distribution. The forceps indicates the site of anastomosis (Fig. 1,a). After release of the vascular clamp, thermal coronary angiography shows immediate antegrade perfusion of the LAD, as well as retrograde filling of a first diagonal branch, documenting graft and anastomotic patency. Thermal 